\title{
Trabalho e Educação: elementos para pensar a fomentação do precariado juvenil no Brasil do século XXI
}

Work and Education: elements to think about the development of the precarious youth in Brazil of the 21st century

\begin{abstract}
Resumo:
O artigo apresenta uma reflexão sobre a formação do precariado no Brasil do século XXI, demonstrando como as mediações entre as políticas educacionais e de trabalho têm contribuído para viabilizar e intensificar esta formação. Uma das conclusões aventadas é que algumas medidas políticas no âmbito educacional e do trabalho vem na tentativa de se tornar um amortecedor dos ciclos entre exploração e inserção no exército de reserva, quando viabiliza a oportunidade dos jovens obterem um treinamento para o mercado e o ingresso na educação superior possibilitando a continuidade deste ciclo.
\end{abstract}

Palavras-chave: Educação, Trabalho, Precariado, Juventude.

\begin{abstract}
:
The article presents a reflection on the formation of the precariat in Brazil twenty-first century, demonstrating how the mediations between education policies and labor has helped to facilitate and intensify this training. One of the conclusions is that some policy measures in the education sector and labor, is trying to become a damper cycles between exploitation and integration into the reserve army, when enables the opportunity for young people to obtain training for the market and entry into the higher education enabling the continuity of this cycle.
\end{abstract}

Key words: Education, Labor, Precariat, Youth.

\section{Introdução}

As ações estratégicas direcionadas para os segmentos do precariado juvenil brasileiro ao longo do século XX e XXI acompanham as transformações econômicas, sociais, políticas e culturais que desencadearam ao longo dos anos, estudos e perspectivas distintas para se tratar a questão do desenvolvimento econômico, da pobreza e das desigualdades sociais, regionais em todo o país. O que permitiu configurar formas diferenciadas de tratamento conceitual e político para as questões postas para a juventude. Este direcionamento começa a ganhar fôlego na necessidade de busca de superação do subdesenvolvimento no Brasil nas décadas de 1960/1970, que motivou discussões sobre o desenvolvimento econômico e social. Nesta contextualidade, a questão urbana ancorada pelos processos migratórios promovidos pelo chamado êxodo

\footnotetext{
* Professora da Faculdade Vale do Jaguaribe. Doutorado em Serviço Social pela Universidade Federal de Pernambuco. E-mail: milenagmedeiros@yahoo.com.br
} 
rural, a constituição das favelas e o aumento populacional nas grandes metrópoles, ganha centralidade nas discussões, incorporando à necessidade de propor medidas que viabilize o desenvolvimento e o controle destes processos.

Somente nos anos de 1970 que as questões ligadas à pobreza e ao êxodo rural passam a ser identificadas por alguns estudiosos como frutos das contradições do sistema sócio-metabólico do capital, que produz e reproduz um exército de reserva para as necessidades de expansão do desenvolvimento do capital. A tônica do debate crítico do subdesenvolvimento da economia dependente, ainda permanece com força em que as questões da pobreza e o que chamava de marginalidade desembocou em várias ações militaristas de controle e repressão associadas à expansão de políticas nesta década. Uma expansão que foi direcionada ao sabor dos organismos internacionais, a exemplo do Banco Mundial, que postulava dispender financiamento, no que concernem as instituições de educação eram um contrassenso, pois defendiam a generalização do ensino técnico e profissional no país, consideradas modalidades adequadas às necessidades dos países em desenvolvimento.

Nos anos de 1980, ainda submerso à ditadura, e suas implicações regressivas no campo dos direitos políticos e civis, bem como, do aumento da pobreza, ganha evidência além das questões políticas e cívicas, (...) chama-se a atenção para a questão da democracia, [...] a falência das ditas políticas sociais, os movimentos sociais, as lutas sociais (VÉRAS, 2001, p. 31). E deste modo, os estudos sobre a marginalidade vai cedendo espaço para a discussão de cidadania e a reconstrução de espaços entre a ditadura e a cidadania. Este espaço segue às diretrizes do Banco Mundial, que sofre uma inflexão em direção ao ensino elementar.

No que tange à seara política, a juventude intensifica sua participação reivindicativa no país contra a ditadura militar, em prol do movimento das Diretas Já. No momento da afirmação democrática do país pela aprovação da Constituição que postulou as eleições diretas para todos os cargos e à legalidade dos partidos políticos; a juventude durante a constituinte se une para legitimar o voto facultativo de 16 e 17 anos, o que passou a expressar um novo peso desta juventude no Brasil.

Somente nos anos de 1990 que se verificam algumas ações para a juventude no momento em que, alguns planos locais e regionais passam a dar centralidade à questão da juventude e propor diretrizes e ações para atingir as metas instituídas pelos planos. 
Como também, é o momento que várias parcerias são efetuadas com o setor privado, o Estado e as organizações da sociedade civil para auxiliar na execução dos projetos e programas. Nesta década, a inflexão neoliberal não apenas permanece válida como é radicalizada. A centralidade adquirida pela educação no discurso do Banco Mundial nos anos 1990 ganha contornos privatizantes, e mercantilistas. Por outro lado, sinalizam-se as primeiras políticas de expressão para a juventude. E estas, foram desenvolvidas sob o conceito de exclusão social para tentar explicar as chamadas novas assimetrias sociais geradas pelas transformações tecnológicas no mundo do trabalho e pela globalização da economia, o que significava dizer que os excluídos eram aqueles que não tinham acesso aos direitos de cidadania. Posteriormente, o entendimento postulado por Castel (1998) de desfiliados sociais ganha força, atentando à chamada exclusão social, que para o autor tinha perdido sua funcionalidade, uma vez que, os sujeitos de fato não eram excluídos do âmbito produtivo e nem de outras esferas sociais. Agora, o que existe seria um processo de desfiliação posta pela desconfiguração da sociedade salarial, o que impulsou o surgimento de novos pobres, ou seja, de uma nova questão social. (CASTEL, 1998).

Ainda que, a conjuntura de crise de desemprego, informalidade, desestruturação dos salários e da proteção social, seja de fato, uma realidade identificada, asseveramos que além destas questões, a expansão do exército de reserva continua sendo uma estratégia do sistema para regular o preço da força de trabalho, permitindo a reprodução das condições de existência do sistema. Quanto ao termo exclusão e nova questão social, desconsideramos sua utilidade, já que se apresenta como conceitos ideológicos, que mais escondem do que revelam as contradições de inserção precárias e existência do exército de reserva no sistema do capital, que se expressa de formas variadas, mas que mantém o conteúdo da exploração/alienação das relações de trabalho capitalistas.

No item seguinte discutiremos as relações entre educação e trabalho, enquanto mediações precípuas para a fomentação do precariado no Brasil.

\section{Educação e trabalho: o precarizado em formação}

A agenda dos projetos e políticas para a juventude no Brasil inicia-se nos anos 1990, articulada pelos organismos internacionais que após a escolha em 1985, definido 
como ano da juventude pela Organização das Nações Unidas (ONU), que elegeu o debate articulando com fulcro temático - juventude: participação, desenvolvimento e paz; refletindo na instauração dos primeiros conselhos estaduais de juventudes no país, especificamente nos estados de São Paulo e Minas Gerais. Desse modo, a juventude deveria ser compreendida historicamente e processualmente, apreendendo os processos sociais em que os jovens se envolvem com a história, a política, a economia, a diversidade micro e macro regional e a cultura que contribuem para a expressão de seus valores.

Outra agenda importante diante destas questões, diz respeito às elaborações pragmáticas da UNESCO quanto à reestruturação do ensino para a juventude, de modo que, buscava estimular tendências inovadoras no que se refere às:

[...] atividades de utilização da informática na organização dos estudos, o ensino aberto ou à distância, a criação ou o desenvolvimento de redes cooperativas, a integração entre pesquisa e formação dentro de uma perspectiva multidisciplinar para ajudar a resolver problemas de desenvolvimento [...], (DIAS, 2012, p.56).

Confirmando uma tendência pragmática e utilitarista dos processos de ensino e desenvolvimento econômico no mundo inteiro que passou a implementar o modelo europeu representado pelo pacto/reforma de Bolonha. Consolidava-se, assim, uma dita modernização dos sistemas universitários, que facilitaria a produção de conhecimentos, a flexibilidade dos currículos e diplomas, a mobilidade socioeconômica e acadêmica dos jovens.

É necessário pontuar que a questão da mobilidade social, tornou-se foco estratégico das políticas sociais nos países centrais e também periféricos, pautando-se em medidas que buscam mensurar esta questão, e assim, construir bases que legitimem o desenvolvimento social e econômico desses países. A busca por uma suposta mudança na posição social dos indivíduos e ou grupos tem conduzido as políticas de educação e emprego a tornarem canais para tal mobilidade. Para que a mesma aconteça, torna-se preponderante que eclodam mudanças de posição econômica, política e profissional, individuais e grupais que combinadas, constituiriam no que se qualifica como mobilidade social. 
As mudanças conjunturais também têm implicações diante dos processos de mobilidade social, o que tem necessitado uma atenção maior diante dos métodos de desenvolvimento. Este desenvolvimento, por sua vez, tem-se estruturado a partir da mediação das políticas educacionais, de trabalho, de assistência social, dentre outras, que têm procurado construir uma coesão social promovida por esta mobilidade.

Nesta direção, a mobilidade passa a constituir uma pragmática necessária da boa saúde do capital e do trabalho, que para os teóricos do capital, pode ser observada a partir de variadas formas, seja em termos econômicos: geração de emprego, e ocupações, seja, acesso à renda. O que pode ou não evidenciar uma ascensão social.

Assim, indicamos que a tendência que vem se pautando no atual paquiderme do século XXI no Brasil, é de uma mobilidade precarizada, que tem-se constituído como "um novo canto da sereia", que reproduz o discurso da educação, enquanto mediação para o desenvolvimento do país, distribuição de riqueza e diminuição de desigualdades sociais e regionais. Por outro lado, se observarmos de forma mais atenta e menos apressada, identificaremos que do ponto de vista das condições econômicas e sociais propiciadas pelas políticas de inserção educacional, e sócio-ocupacional, as mesmas vêm-se apresentando de forma retardatária, se considerarmos os cortes no orçamento da educação, a taxa de desemprego e desocupação que gradualmente aumenta, e a geração de emprego que vem centralizando-se em postos de baixos salários e em condições e relações precarizadas. O que nos permite dizer que esta mobilidade precarizada move-se dentro da própria estrutura da classe trabalhadora/pobre, em que pouco tem alterado as reais condições de vida. Isto não significa que não tenha ou venha ocorrendo algum tipo de mobilidade intergeracional e/ou intrageracional, mas a extensão e intensidade do que seria apregoado pelas políticas de desenvolvimento e geração de oportunidades, são díspares, nem de longe chega a acontecer de forma ampla e satisfatória, ainda que, observemos que politicamente os jovens têm assumido algumas posições de enfrentamento em defesa de suas demandas e direitos.

Pensar sobre a mobilidade, tendo a educação superior como mediação basilar, significa compreendermos que o Estado aliado ao mercado contribuirá de forma decisiva nos rumos a serem tomados em prol dos processos de acumulação e valorização do capital, e do desenvolvimento do capital humano e social. Já que, historicamente a intervenção do Estado no Brasil, tem acompanhado às determinações 
mais gerais do capitalismo monopolista/flexibilizado, que mediante às necessidades do capital e do trabalho tem reestruturado as respostas diante dos seus projetos,

[..] sempre mediatizada pela correlação de forças entre as classes sociais em presença e, por sua vez, dessas classes com o Estado, possibilita[ndo] a institucionalização de um conjunto de políticas sociais em diferentes esferas da vida social, (AMARAL, 2001, p.01).

Desta maneira, indicamos duas direções para o debate da mobilidade: uma que diz respeito ao movimento do capital que se desloca entre regiões e nações mundialmente, ou melhor, a (trans)nacionalização do capital, e aquela mobilidade possivelmente individual e/ ou grupal, entre os sujeitos em relação ao panorama socioeconômico. Não podemos esquecer que as oportunidades devem ser diversificadas, para que se promova a mobilidade. Nesta perspectiva, a mobilidade social materializaria à justiça social, transformando-se, enquanto indicador de desenvolvimento social e estímulo para o crescimento econômico, se pensarmos em um ciclo de desenvolvimento e de geração de novas expectativas para o futuro. Entretanto, parece que está sendo derruído com a atual crise política e a recessão econômica no Brasil, que nos últimos dois anos (2016 e 2017), muitas mudanças aconteceram e todas as respostas neodesenvolvimentistas da era Lula-Dilma são interditadas no "governo" Temer e substituídas por desmontes pautados no neoliberalismo, agravando os problemas enfrentados pela juventude trabalhadora.

Tendo em vista estas questões ventiladas, torna-se primordial acompanharmos a dinâmica de acumulação do capital em que encontra a relação entre educação e trabalho, o fio condutor para impetrar às mudanças diante dos processos de desenvolvimento econômico e social. O que torna cogente que oriunde-se mudanças no arcabouço legal/jurídico e administrativo do Estado e de suas políticas para gerir as iniciativas neste campo. Sem perder de vista que a educação no Brasil tem um caráter privado.

Vale observar que o setor privado, deteve, historicamente, a hegemonia na apropriação dos recursos destinados à formação profissional. Mais do que isso: a partir dos fundamentos dos "ajustes" - desemprego, recessão, precarização do trabalho, desregulamentação dos direitos do trabalho converte a formação profissional em um dos alvos principais de sua intervenção, dando lhes estatuto de política de emprego, (AMARAL, 2001, p.03). 
Pochamann (2007) salienta que as novas gerações de jovens no Brasil têm grandes possibilidades de ultrapassar as condições de vida e trabalho de gerações anteriores e ascender na trajetória profissional. Para o autor (2004, p. 218):

Foi com o avanço das políticas públicas endereçada de financiamento da inatividade dos jovens por intermédio de bolsas de estudos [..] como forma de elevar a escolaridade e a formação que as condições de disputa no mercado de trabalho melhoraram. Trata-se de uma condição essencial, uma vez que o conhecimento torna-se cada vez mais o elemento decisivo na trajetória ocupacional.

Essa ideia tem por base o entendimento de que a juventude tem papel estratégico no âmbito do crescimento econômico e de desenvolvimento do país e por isso, é mister, dado ao atual fenômeno do chamado bônus demográfico, que iniciou em 1995 e segue segundo especialistas como Alves (2008) até os anos de 2055, perfazendo um período de 60 anos. Levar em consideração a participação dos jovens na economia e no mercado de trabalho e para isto o investimento, expansão e ampliação de instituições educacionais e o financiamento mediante as bolsas nas IES privadas, tornou-se mediação estratégica para promover o desenvolvimento do país, aproveitando a atual situação sócio-ocupacional dos jovens na estrutura produtiva e de serviços, uma referência de estágio de desenvolvimento para o país.

Desse modo, a educação passa a ganhar centralidade diante da preparação da juventude para o trabalho, e assim, os tornam mais competitivos para disputar vagas no mercado.

O interessante nas explanações de Pochamann (2007) é que a educação e sua política de qualificação deve ser vista, enquanto, um meio de alcançar a inclusão social, o desenvolvimento econômico, geração de trabalho e renda, como se esta política tivesse condições de realizar estas transformações e ser capaz de impulsionar as mudanças estruturais, que tanto tem sido referenciadas nas discussões sobre o desenvolvimento com justiça social. O que tem acontecido na realidade é a transferência do peso das responsabilidades da formação e inserção no mercado para a juventude, transferindo o ônus da inserção e do pagamento de sua própria qualificação, como se os mesmos fossem capazes de gerar o seu próprio emprego, além de conseguir permanecer nestes. 
A Organização de Cooperação e de Desenvolvimento Econômico (OCDE), também contribuiu no direcionamento das mudanças quanto às políticas para juventude, no âmbito educacional ao adotar, enquanto, política oficial o acesso universal à Educação Superior (ES), ou terciário, [..]. Dessa maneira, a organização preconizava que era necessário a chegada de um novo paradigma para o ensino terciário, que tem como elementos, entre outros, os seguintes: "a orientação, em um grande número de países, de ações realizadas pelas autoridades públicas que preveem à possibilidade de admissão ao ensino terciário de $60 \%, 80 \%, 100 \%$ de todos os que completarem seus estudos secundários", (DIAS, 2012, p. 68).

Dessa forma, os países da América Latina e em especial o Brasil passaram a adotar o modelo europeu bolonhês, que além de propor uma mudança na estrutura do ensino, na missão da universidade, pauta-se na objetivação de um novo tipo de sociedade e relações de trabalho mais flexíveis, com valores guiados pela concepção mercadológica e empresarial. Consolidando uma unidade política e cultural de uma contrarreforma no campo da educação e de outras políticas sociais, com um diferencial: as políticas implementadas no Brasil tem-se direcionado para desenvolver o processo de acumulação e formação de força de trabalho, no interior dos municípios brasileiros, a fim de fomentar o desenvolvimento econômico com justiça social. Ainda, que a postulação de Dias (2012) tenha validade, os jovens brasileiros são orientados a permanecerem em suas localidades e contribuir com os processos de desenvolvimento. Assim, deve-se

[...] liberar o mecanismo de mercado e fortalecer o seu papel no desenvolvimento econômico. O setor privado deveria ser o motor do crescimento com o governo desempenhando um papel de apoio a ele. 0 crescimento [..] econômico seria o principal meio pelo qual a pobreza seria aliviada, (LEHER, 1999, p.06).

A partir dos anos 2000, o debate sobre as questões da juventude tem ganhado mais densidade no âmbito das universidades, quando foi instituído entre 2002 e 2003 “os primeiros Observatórios de Juventude em instituições universitárias brasileiras, em parceria com a UNESCO, que na oportunidade lançou o Observatório de Violência nas Escolas", (BRASIL, SECRETARIA NACIONAL DE JUVENTUDE, 2011, p. 20). Observa-se neste ínterim, que o direcionamento das propostas da UNESCO, passa a ser seguidas de forma estratégica para implementar um projeto para a juventude nos países periféricos. 


\section{A nova agenda política para a juventude}

A formulação das políticas para a juventude ganha uma nova formatação conceitual à medida que passa a englobar um conceito alternativo de exclusão social e desfiliação social, o que se dá mediante o termo de vulnerabilidade social. Este termo remete às questões ligadas, ao que os ideólogos das políticas nomeiam de risco, fragilidade ou possibilidade de dano. O que se contrapõem, nestes termos, ao sentido de potencialidade ou capacidade, enquanto, resposta dos sujeitos e das políticas às situações adversas de vulnerabilidade.

Aventa-se, que o entendimento do termo vulnerabilidade será a chave para a formulação de várias políticas, partindo do pressuposto de que existe um resultado negativo entre o que se disponibiliza de recursos materiais e simbólicos dos sujeitos individuais e/ou em grupos e ao acesso às oportunidades sociais, econômicas, culturais que provêm do Estado, mercado e sociedade. A partir disto, as políticas de educação, trabalho, assistência, dentre outras, serão consideradas como insumos básicos para o desenvolvimento destes recursos materiais e simbólicos, proporcionando ao acesso a bens e serviços, permitindo que as oportunidades sejam adquiridas, reduzindo as situações das chamadas vulnerabilidades sociais, num contexto que "imperam a insegurança econômica, a total falta de perspectivas, [..] e a precariedade em cada fase da própria existência", (VASAPOLLO, 2004. p.01). Precariedade esta, que tem conduzido ao aumento da instabilidade e segurança dos rendimentos e da própria condição de vida.

Nesta perspectiva, o Brasil incorpora nas suas políticas este entendimento, associando os direcionamentos postos pelos organismos internacionais desde os anos de 1990, passando a realizar entre 2004 e 2005 um estudo sobre Juventude Brasileira e Democracia: participação, esferas e políticas públicas, que constatou várias preocupações dos jovens como: violência, trabalho e educação, passando a repensar as estratégias neste campo.

Em 2004, assistimos à culminância da Conferência Nacional de Juventude, que originou um marco para a construção das políticas públicas de juventude,

[..] como resultado, a conferência apresentou subsídios à formulação da Emenda Constitucional 65, que insere a juventude como público prioritário 
na Constituição, do Plano Nacional da Juventude[..], e o Estatuto da Juventude, que reafirma os direitos dos jovens, (SECRETARIA NACIONAL DE JUVENTUDE, 2011, p. 21).

Este período avança, no que diz respeito ao desenvolvimento de uma nova agenda para a juventude brasileira, ao passar a discutir propostas em várias dimensões, em que as mediações do trabalho e educação passam a ganhar pauta necessária e presença efetiva no marco das legislações, dos programas e políticas. Assim, em 2005 é implantado a Secretaria Nacional de Juventude (SNJ), o Conselho Nacional de Juventude (CONJUVE) e o Programa Nacional para Inclusão de Jovens (PROJOVEM) e posteriormente a Política Nacional da Juventude (PNJ).

Essas ações foram desenvolvidas com o apoio dos organismos internacionais, a exemplo da UNESCO, que elaborou o Índice de Desenvolvimento Juvenil- IDJ, que permite identificar, ou melhor, focalizar, os jovens em chamada situação de vulnerabilidade social, e estruturar um leque de ativos para promover as oportunidades e as capacidades. Este índice segue os indicadores de renda, educação e saúde apregoado pelo Índice de Desenvolvimento Humano (IDH), do Programa das Nações Unidas para o Desenvolvimento (PNUD) em que analisa, especificamente, os jovens de faixa etária de 15 a 24 anos. 0 índice varia de 0 a 1 anos, de onde quanto mais próximo de zero, pior são as condições de vida dos jovens. Dessa maneira, os processos educacionais, o acesso precário ou não acesso à renda, e o desemprego são considerados indicativos de vulnerabilidades no segmento juvenil e assim, são pautados como possibilidade de que, os ativos na educação, trabalho e renda sejam favoráveis ao desenvolvimento das oportunidades, capacidades e mobilidade social.

Vale salientar que o índice permite que se tenha um panorama geral da situação da juventude brasileira, mediante à mensuração das questões econômicas e sociais. Desta forma, o índice se utiliza do indicador analfabetismo, escolaridade adequada e qualidade do ensino, mortalidade por causas internas e causas violentas e por último, a renda familiar per capta. Esses indicadores foram combinados para estruturar os três índices parciais: de educação, de saúde e de renda, contribuindo para que os países tenham um panorama geral sobre a situação da juventude em suas localidades e possam estruturar sua agenda de políticas para este segmento. A partir deste momento, o Brasil, passa a fomentar suas políticas, observando os eixos propostos pela UNESCO, Banco 
Mundial, OCDE, e assim, instituir várias contrarreformas no campo da educação, especialmente, a superior, como também, no campo das políticas para o desenvolvimento do emprego e da qualificação técnica para o mercado. Assim, "a redefinição dos sistemas educacionais está situada no bojo das reformas estruturais [..], guardando íntima relação com o par governabilidade-segurança", (LEHER,1999, p.01).

Entender o caráter dominante das ideologias que informam a reforma educacional pode ser evidenciado em vários documentos dos organismos internacionais que apresentam suas concepções ideológicas, traduzidas em ações práticas e teóricas. Um exemplo desta questão está no relatório da PNUD /2014 que trata o desenvolvimento a partir da questão da sustentabilidade do progresso humano, a partir da redução das vulnerabilidades e do reforço da resiliência. O relatório deixa claro que a questão da vulnerabilidade não significa sinônimo de pobreza, mas dos riscos, da insegurança, dos choques ambientais, econômicos e de saúde como também o stress, as guerras e conflitos que podem gerar condições negativas para o desenvolvimento humano e econômico dos países. Evitar estas questões significa reduzir às vulnerabilidades a que os indivíduos estão expostos e avançar no processo de desenvolvimento. Nesta perspectiva, a formulação de políticas e ações que promovam à prevenção e o reforço nas capacidades dos indivíduos, deve ser fortalecida enquanto resposta às problemáticas socioeconômicas e culturais elencadas.

Mediante o exposto, as estratégicas para reduzir às vulnerabilidades e reforçar a resiliência, requereu-se desenvolver algumas linhas de ações, tais como: 1- dotar as pessoas e as sociedades de competências para enfrentar os choques econômicos, ambientais e de saúde, o que impõem a alteração das leis, das políticas, dos investimentos, dos valores e princípios, que venham permitir a manutenção da direção e dominação hegemônica do capital sob o trabalho nos países desenvolvidos e periféricos; 2- Para isto, a educação, sobretudo, dirigida aos mais jovens, contribuirá na capacidade de adaptação dos mesmos aos momentos de crise. Outra questão, diz respeito à 3-proteção social e institucional terá a capacidade de responder a quem necessitar, possibilitando diminuir os impactos adversos suscetíveis para as gerações futuras. Para isto, será necessário adaptar as instituições aos objetivos e metas definidas internacionalmente e pactuadas pelos países em desenvolvimento. Ou seja, estas ações estratégicas vem reforçar a corresponsabilidade entre os indivíduos e o mercado, além 
disso, reafirmar a flexibilidade das relações sociais, dos processos de trabalho, da formulação das leis, e das políticas sociais e econômicas ante as respostas do estado e do mercado, a busca pela coesão social desconsiderando as lutas e conflitos de classe, o que faz conjecturar a fomentação de uma nova sociedade do conhecimento, que requer e demanda de mudanças na capacidade de resposta dos indivíduos e da busca pela chamada boa governança, em prol do desenvolvimento.

O interessante é que a questão da resiliência individual e comunitária, é colocada como um fim a ser conquistado no alcance da redução das chamadas vulnerabilidades, mediante políticas conexas aos eixos da proteção, prevenção e promoção, que inclui as ações de investimentos do Estado e do mercado na fomentação da capacidade de adaptação, e passividade dos indivíduos, defronte das mudanças regressivas da sociabilidade do capital.

Portanto, a resiliência deve ser reforçada para que, as capacidades e competências sócio/individuais sejam fortalecidas na direção do mercado.

O robustecimento, das políticas de desenvolvimento, a ser seguido a partir de metas, princípios e normas incorporados em políticas específicas para atingir as determinações dos processos de desenvolvimento econômico e social têm por base o investimento no capital humano e social, as contrarreformas educacionais, além da exaustão de programas socioassistenciais e educacionais, que retomam à relação entre desenvolvimento e equidade social e trazem um novo projeto de desenvolvimento para os países, para as regiões e para os sujeitos. Trata-se, pois, de um modelo de desenvolvimento que articule estas questões, mas que implemente medidas cambiais, fiscais e monetárias assentadas por uma política macroeconômica que privilegie o superávit, o pagamento das dívidas, o financiamento privado, e a segurança da propriedade privada, o que pressupõe, uma economia de mercado forte, aliada a um Estado, também forte em suas ações direcionadas para este fim e que combate à exclusão e ou vulnerabilidade social, para se utilizar os termos dos intelectuais do capital, a partir de políticas econômicas aliadas à promoção da equidade entendida como igualdade de oportunidades.

De acordo com a Organização para a Cooperação e o Desenvolvimento Econômico (OCDE), 
As perdas futuras de bem-estar como a situação em que as pessoas não possuem ativos que são cruciais à resiliência perante os riscos. E propõe um conjunto de indicadores destinados a avaliar a vulnerabilidade de uma sociedade com base no acesso a diferentes tipos de capital: econômico (pobreza), humano (educação) e social (redes de apoio), bem como a bens coletivos, como serviços essenciais. (PNUD, 2014, p. 40).

Desse modo a função do Estado, é

[...] atuar no incentivo ao direcionamento dos ativos financeiros privados, [..]. O controle das principais variáveis macroeconômicas - câmbio e juros - por meio da política econômica estatal será capaz de assegurar condições seguras e estáveis para a retomada dos investimentos privados e públicos, gerando crescimento econômico, [..] empregos e distribuição de renda, [..] e oportunidades, (CASTELO, 2007, p. 04).

Isto significa que o Estado, mercado, família, cultura, educação, trabalho, entre outros, terão papeis específicos na trama do desenvolvimento em direção ao crescimento econômico, e manutenção da hegemonia ideopolítica capitalista, que se exemplifica, no que hoje os ideólogos qualificam como resiliência (capacidade de resposta e adaptação as circunstâncias). Destarte, os ativos no campo da educação procurarão fomentar competências e adaptações necessárias ao desenvolvimento aprofundando juntamente com as redes de apoio a coesão e a solidariedade social no campo da prevenção da fragmentação, e dos conflitos.

Em vista disso, o êxito das políticas e da chamada boa governança, será dado pelas respostas articuladas ao capital econômico, no campo das ações contra a pobreza, capital humano com a educação e o capital social com as redes de apoio e oportunidades sociais. Em tempos de crise estrutural do capital, assistimos ao acirramento do financiamento público, destinado ao setor privado para salva guardar os oligopólios empresariais, renovando assim, a agenda de acumulação do capital nos países periféricos.

Nesta direção, as conexões entre educação e pobreza também fornecem o substrato das reformas educacionais em curso, como também nos permitem visualizar as estratégias do que os ideólogos do capital entendem como desenvolvimento integrado, que comporta ações e políticas nos campos da economia, no campo social, político, do trabalho, da educação, dentre outras. É neste contexto, que se fomentará diversos programas que atenderão diretamente as populações tidas como vulneráveis e que, possivelmente podem ser sensíveis a direcionamentos mais críticos. 
Deste jeito, para que os países periféricos homogeneízem, ainda que, com suas particularidades, a pragmática das respostas à pobreza e à insuficiência de capital humano e social, instaura assim, uma nova ordem de demandas e respostas do capital e do trabalho, problematizadas mediante à conceituação de concepções como vulnerabilidades, riscos, resiliências fomentando a nova estrutura das políticas sociais e educacionais implementados no Brasil, que trará o combate da pobreza e das desigualdades econômicas, sociais, educacionais e regionais como foco de ação.

Cabe precisar que a conceituação do termo vulnerabilidades e seus adjacentes trazem na realidade, um sentido muito abstrato e vazio, tendo em vista, que as relações sociais capitalistas produzem e repõem constantemente processos e relações que desaguam na reprodução ampliada e crescente da desigualdade, pobreza, e do exército de reserva. O que indica, que a vivencia do que os ideólogos qualificam como riscos e choques são na verdade as implicações dos processos de desenvolvimento do sistema do capital, de onde variadas formas são fomentadas pelos seus ideólogos para administrar os processos mais acirrados destas implicações. Entendemos que administrar riscos e choques não coloca os sujeitos em outra estrutura socioeconômica, pode até minimizar as problemáticas mais superficiais, mas não muda o sócio metabolismo do capital de produzir riqueza, aliado à pobreza, miséria e o seu exército de reserva. Prova disto, é a expansão deste exército de desempregados que já chega a $11 \%$ segundo os dados da IPEA/2017.

Estas questões são relevantes porque vão se desenhar um novo projeto para a juventude em que, os jovens pobres são tratados como aqueles que necessitam fomentar capacidades a partir de oportunidades implementadas pelo Estado e mercado. Sob esse prisma, as questões socioeconômicas, históricas e educacionais que perpassam a complexidade do entendimento da juventude, tornaram-se alvo de propostas dos organismos internacionais e recomendações para o países periféricos, no que diz respeito à construção de uma nova pragmática para a juventude na direção de um desenvolvimento econômico e um desenvolvimento integral, compreendendo e articulando alguns eixos considerados significativos para o alcance desta nova pragmática, e construção das novas identidades, perspectivas, trajetórias e relações dos jovens diante dos processos de desenvolvimento econômico e regional. Assim, a noção 
de desenvolvimento integral articula educação, trabalho, inovação/tecnologias, dentre outras.

Do ponto de vista da articulação entre as dimensões de educação e trabalhos, vários autores (LANGONI,1973; MENDONÇA, 1996; FERREIRA, 2000) expõem que um dos elementos explicativos das desigualdades de renda no Brasil, estaria justamente nas diferenças educacionais ou melhor nas desigualdades educacionais acumuladas ao longo dos anos, chegando à disparidade de 30 a $50 \%$ da renda provinda das desigualdades educacionais. Para estes autores, a educação seria decisiva para o incremento da renda, mediante cada ano de estudo, que em termos percentuais ficaria em torno de $2,2 \%$ de chance de trabalho remunerado para cada ano de estudo, (PNAD, 2001).

Sob este horizonte, vários programas foram desenvolvidos, seja no âmbito da educação básica ou superior na busca de minimizar os limites apontados pelas diferenças de renda e do padrão de acesso e qualificação dos jovens na educação e no mercado de trabalho. Para citar alguns no campo da educação superior, temos: Programa de Apoio a Planos de Reestruturação e Expansão das Universidades Federais - REUNI, instituído desde 2007 o Programa Universidade para Todos - PROUNI, instituído desde 2004, o Fundo de Financiamento ao Estudante do Ensino Superior FIES, instituído desde 1999, o Plano Nacional de Assistência Estudantil - PNAES, instituído desde 2008, o Programa Institucional de Bolsas de Iniciação Científica, instituído desde 2009, entre outros.

Não podemos deixar de fazer alusão às duas leis que foram instituídas como formas de viabilizar as transferências dos recursos públicos para o setor privado. Estamos nos referindo à lei no. 10.973, criada em 2004 que incentiva as inovações tecnológicas. Esta lei facilita a utilização de recursos, físicos, materiais e humanos, e a transferência de tecnologias das universidades para as empresas, como também tem viabilizado à alocação de recursos para projetos, dito de inovação das empresas. A problemática que esta lei traz, diz respeito à mudança de função social das universidades no campo científico e da inovação que vem favorecendo a iniciativa privada, além de que, converte o docente em "empreendedor" que passa a ser remunerado mediante sua capacidade produtiva. Outra ação foi à lei (n. 11079), outorgada em 2004, que prevê as parcerias do Estado com o setor privado nos mais 
variados ramos (produção, comércio de bens, serviços de educação, ensino, dentre outros).

De acordo com o Sindicato Nacional dos Docentes das Instituições de Ensino Superior (ANDES, 2004), o setor privado tem-se beneficiado dos contratos de parcerias público-privado que para a educação, o Estado tem tratado a questão como a prestação de um serviço de bem público e ou de interesse social. E por último, citamos o projeto de lei (7.200/06), que busca estabelecer uma nova regulamentação para a educação superior no Brasil. Este foi encaminhado para o Congresso Nacional em junho de 2006, ainda não aprovada. O que não significa que as ações e medidas da contrarreforma no campo educacional não venha acontecendo. Prova cabal disto está na formulação e implementação dos programas, projetos, leis de parcerias com o setor privado materializados cotidianamente.

Estes programas foram desenvolvidos entre 2003 - 2010, durante os mandatos dos governos de Luiz Inácio Lula da Silva, ainda que o Financiamento Estudantil (FIES), por exemplo, tenha-se iniciado no governo FHC. O que permite, dizer que estes programas, estavam em pleno desenvolvimento durante o governo Dilma, enquanto continuidade da busca pelo desenvolvimento econômico para o país; em que a juventude passa a ser considerada foco estratégico para este desenvolvimento. No entanto, durante nos últimos dois anos (2016 e 2017), muitas mudanças aconteceram e as respostas neodesenvolvimentistas da era Lula-Dilma foram interditadas pela atual administração golpista do presidente Temer e substituídas por desmontes pautados no neoliberalismo (Emenda Constitucional 95 - teto dos gastos: Reforma Trabalhista, Reforma da Previdência, Reforma do Ensino Médio, entre outras), os quais vem acirrando ainda mais os problemas enfrentados pela juventude trabalhadora.

Não podemos deixar de pontuar, que a ampliação do acesso à educação constitui uma demanda histórica e de luta dos movimentos sociais e dos sujeitos coletivos. Para citarmos alguns pontuamos: o esforço da Associação Nacional de Docentes de Ensino Superior (ANDES), e no âmbito do Serviço Social, o Conselho Federal de Serviço Social (CFESS), Associação Brasileira de Ensino, Pesquisa e Extensão em Serviço Social (ABEPSS), Executiva Nacional dos Estudantes de Serviço Social (ENESSO), que vem se posicionando contra a privatização e mercantilização da educação superior absorvida pela Política Nacional de Educação no Brasil. Vários debates, fóruns, discussões, 
documentos e manifestações vem sendo pautados recusando tal política, que têm-se fomentado e seguido as orientações do Banco Mundial mediante seus organismos financeiros multilaterais (BIRD, FMI, OMC, UNESCO, CEPAL) quanto à realização da contrarreforma da educação nos países periféricos.

Assim sendo, as políticas e os programas têm-se pautado no princípio da igualdade de oportunidades, este que surge do ideário liberal burguês e que significa a necessidade de eliminar os obstáculos econômicos e sociais dos sujeitos, no que se refere às condições de dispor do acesso ao sistema de ensino concorrencial. Ou melhor, trata-se de reconhecer numa sociedade burguesa, os sujeitos de direitos, típico de uma sociedade de classe e desigual, que só faz sentido quando se cria mecanismos jurídicos que venham amenizar as descriminações, opressões, preconceitos, conterem à ruptura da institucionalidade dos valores burgueses, (SANTOS, 2010).

Sob esse ângulo, essas políticas e programas têm buscado propiciar à equalização do acesso e permanência dos jovens à educação superior. O que de fato, vem acontecendo do ponto de vista do acesso, porém, não se verifica diante das condições de permanência. Não constituindo uma realidade em expansão, já que, muitos jovens ainda desistem dos cursos por falta de uma política de assistência estudantil que venha a responder com mais afinco suas necessidades; outros por não conseguir conciliar trabalho e estudo, dentre outros motivos. Outra questão que deve ser levada em consideração é que esses programas buscam contribuir para a inserção dos jovens no mercado de trabalho, atendendo uma demanda excluída da universidade, e ao mesmo tempo, atua em benefício da recuperação financeira das instituições privadas endividadas, com alto índice de inadimplência e desistência, o que acaba ganhando um maior número de renúncia fiscal em troca de um número limitados de oferta de bolsas.

Por conseguinte, o estabelecimento desta meta tem a ver com a política de acesso, expansão e interiorização do ensino superior no país, a partir das determinações do Banco Mundial (BM), donde as universidades e faculdades públicas e privadas, passam a considerar para materializar esta meta a realidade regional e a complexidade das desigualdades visando atingir às demandas postas pelo espaço urbano e do campo, ampliando desta forma, a oferta de cursos, sejam eles diversificados e noturnos, ao acesso mediante as bolsas, já que verificou-se que o acesso dos jovens entre 18-24 alcançou um patamar de $13 \%$, muito aquém do que foi posto pela meta de $30 \%$ 
estabelecido pelo Plano Nacional de Educação (PNE/2011). Além disto, os marcantes índices de desigualdades, se comparadas do ponto de vista de renda, de localização geográfica, no que se refere à frequência à educação superior, são alarmantes.

Assim, as propostas de interiorização deste nível de ensino serão postas como estratégia para ampliar as oportunidades de acesso da população do interior urbano e do campo, promovendo o desenvolvimento econômico das regiões e a permanência destes jovens no interior de suas localidades.

No que se refere às políticas de trabalho para a juventude, verifica-se, que

[...] contemplam iniciativas que vão desde aquelas que elevam a escolaridade e a qualificação [..] que favorecem direta e indiretamente a sua inserção no mercado de trabalho, incluindo a criação de contratos especiais de trabalho, o estímulo a iniciativas de autogestão, formas de economia solidária ou formas especiais de relacionamento das empresas com os jovens como forma de estimular a sua contratação". (SECRETARIA NACIONAL DE JUVENTUDE, 2011, p.38).

O modo dominante de apreender a relação entre trabalho e educação orienta-se por algumas dimensões como: a dimensão moralizante em que trata a relação entre trabalho manual e intelectual como igualmente dignos formadores do caráter e da cidadania; a dimensão pedagógica que traz o trabalho como um laboratório de experimentação e por último, a dimensão socioeconômica em que traz o discurso de que os filhos dos trabalhadores podem autofinanciar seus estudos, (FRIGOTTO, 2002). Todas estas dimensões se materializam na busca pela mobilidade precarizada dos jovens, na educação e no mercado de trabalho.

Dentre alguns programas, que tendem a materializar essas dimensões, podemos citar o Programa Unificado da Juventude (PROJOVEM): adolescente, campo, trabalhador, urbano, o Programa Nacional de Integração da Educação Profissional ao Ensino Médio na Modalidade de Jovens e Adultos (PROEJA), o Programa Nacional de Acesso ao Ensino Técnico e Emprego (PRONATEC), o estímulo ao empreendedorismo considerado uma saída para geração de trabalho e renda para jovens dos 18 aos 29 anos, dentre outros.

A estrutura destes programas se dá mediante uma relação que se estabelece entre juventude e trabalho, buscando qualificar/profissionalizar, ainda que minimamente, os jovens para atender às necessidades do mercado de trabalho, proporcionando oportunidades de inserção, acelerando a escolaridade dos jovens de 
baixa renda, e assim, combinando a elevação da escolaridade com qualificação profissional e trabalho, o que torna um elemento explicativo da reversão da questão do desemprego juvenil. Desta forma, a estratégia das políticas de formação para a inserção vem sendo consideradas propulsoras do emprego e antídoto do desemprego. Pois,

\begin{abstract}
Compete à educação operar as contradições da segregação, propiciando aberturas para o futuro. $O$ pressuposto, aqui presente, é: todos aqueles que fizerem as escolhas educacionais corretas terão possibilidades ilimitadas. Os indivíduos (e países) que priorizarem corretamente a educação terão um futuro radioso pela frente, comprovando, deste modo, a validade das bases do sistema. O capitalismo atual é justo com aqueles que souberem se qualificar corretamente. Basta não insistir nas prioridades erradas. Não adianta gastar com o ensino superior e a pesquisa, pois, conforme a tese das vantagens comparativas, os países em desenvolvimento devem perseguir nichos de mercado onde seja possível vender mercadorias de baixo valor agregado, (LEHER, 1999, p.11).
\end{abstract}

Estas questões explicam em parte, as diretrizes do Banco Mundial, da OCDE, UNESCO para o ensino superior, ainda que possibilitem o acesso à educação e ou até ao mercado, não conseguem viabilizar uma mudança real nas condições de trabalho, já que a maioria dos jovens se inserem em relações informais e quando se encontram em relações formais de trabalho, tem enfrentado baixos rendimentos e ausência de proteção social, elevadas taxas de rotatividade, principalmente, por estarem em trabalhos precários, muitas vezes, de caráter temporário. Esta realidade piora se comparamos o desemprego de jovens entre 16-24 anos em função, "do sexo, da condição socioeconômica da família, a idade e da região de domicílio, reproduzindo em si as desigualdades de raça, gênero e renda presentes na população brasileira como um todo", (SECRETARIA NACIONAL DE JUVENTUDE, 2011, p.40-41).

O que muitas vezes, inviabiliza a continuidade dos estudos, pois muitos estão na situação de trabalho precário e ou inseridos no exército de reserva. Nesta direção a Organização Internacional do Trabalho (OIT- 2009), postula que a América Latina, e em especial o Brasil, deve construir uma agenda nacional do trabalho para a juventude, já que,

[...] a juventude brasileira é uma juventude trabalhadora. Mesmo considerando a diminuição das taxas de participação no mercado de trabalho nos últimos anos [...] e que tem-se esforçado para combinar trabalho e estudo. Inversamente, o relatório da agenda nacional para o trabalho decente no Brasil em 2010, divulgou que o [..] aumento dos anos de escolaridade não produziu adiamento significativo do momento de ingresso no mercado de 
trabalho, ampliando-se a parcela dos que buscam articular trabalho e educação em suas trajetórias, (MINISTÉRIO DO TRABALHO/RELATÓRIO DA AGENDA NACIONAL DE TRABALHO DECENTE PARA A JUVENTUDE NO BRASIL, 2010, p. 07).

De acordo com a Agenda de Trabalho para a Juventude formulada pela Organização internacional do Trabalho (OIT), traçou-se enquanto meta prioritária, atingir vários níveis de escolarização com foco na ampliação do acesso ao ensino superior e à qualificação profissional. A OIT (2009) vem defendendo a ideia que a democratização do acesso à educação, formação e qualificação, constitui condição necessária para promover o que a organização qualifica o chamado trabalho decente para os jovens. O que na realidade, evidencia uma juventude inserida em jornadas extensas de trabalho, informalidade e rotatividade, imersas ora na parcela desempregada fora dos circuitos do mercado, ora no exército de reserva, seja latente, flutuante e ou estagnada.

\section{Considerações finais}

A juventude brasileira é uma juventude trabalhadora, que tende a conciliar trabalho e estudo. Em sua maioria, imersas à condições precárias nas suas relações de trabalho e de estudo. $\mathrm{O}$ que vem se fomentando um perfil de jovem precariado, que tem-se relacionando de forma diferente com o acesso aos programas relativos ao trabalho e a educação. De um modo geral, esses programas vem na tentativa de se tornar um amortecedor dos ciclos entre exploração e inserção no exército de reserva, quando viabiliza, ainda que minimamente, a oportunidade dos jovens obterem um treinamento para o mercado e assim ter acesso, ainda que precário, a um rendimento. Promove também a formação de uma demanda de jovens aptos para o ingresso na educação superior, possibilitando a continuidade deste ciclo. Por outra via, fomentamse um exército de reserva no campo da profissionalização técnica para as necessidades da acumulação e rebaixamento do valor da força de trabalho dos ativos.

Não podemos esquecer que o Brasil vivencia um momento singular, marcado pelo bônus demográfico no âmbito da população juvenil em idade e inserção no mercado de trabalho. O que faz o Estado optar em expandir e inserir a juventude na educação superior e no mercado de trabalho, constituindo-se numa escolha estratégica para o país no que se refere ao processo de desenvolvimento nacional. 
Outra questão preponderante a ser ressaltada é que o discurso da democratização foi utilizado como um pretexto para expandir de forma generalizada as instituições privadas e por outro lado, identificamos, que o problema não está na ausência de qualificação para o trabalho, por hipótese seria a causa explicativa do desemprego, e substancialmente faz parte da "boa saúde do capital" em produzir e reproduzir o exército de reserva, mas é justamente no foco -produção/reprodução do exército de reserva, que está a verdadeira essência e substancialidade da expansão das políticas de acesso à educação superior associado a busca da maior mobilidade acumulativa do capital.

\section{Referências}

ALVES, José E, Dinis. A transição democrática e a janela de oportunidades. São Paulo: instituto Fernand Braudel, 2008.

AMARAL, Angela Santana. Qualificação, sociedade civil e desidentidade de classe: os desafios para o sindicalismo. In: Revista Outubro, 2001.

ANDES. Proposta para a universidade brasileira, n.02, Brasília, 2003. Acesso em: http: andes.org.br/publicacoes caderno andes gtpe.pdf.

BARROS, R. P. de; MENDONÇA, R. S. P. Os determinantes da desigualdade no Brasil. Economia brasileira em perspectiva - 1996. Rio de Janeiro: IPEA, 1996.

BRASIL. SECRETARIA NACIONAL DE JUVENTUDE, 2011, 2014. . MINISTÉRIO DO TRABALHO/RELATÓRIO DA AGENDA NACIONAL DE TRABALHO DECENTE PARA A JUVENTUDE NO BRASIL, 2010.

CASTELO, Rodrigo Branco. CRESCIMENTO ECONÔMICO E EQÜIDADE SOCIAL: o modelo novo-desenvolvimentista de intervenção sobre a "questão social". In: III JORNADA INTERNACIONAL DE POLÍCAS PÚBLICAS QUESTÃO SOCIAL E DESENVOLVIMENTO NO SÉCULO XXI, 2007.

CASTEL, Robert. As metamorfoses da questão social: uma crônica do salário. Petrópolis, Vozes, 1998.

DIAS, Marco Antônio Rodrigues. Inovações na educação superior: tendências mundiais. In: Desafios e perspectivas da educação superior brasileira para a próxima década / SPELLER, P.; ROBL, F. e MENEGHEL, S.M.(Orgs.) - Brasília: UNESCO, CNE, MEC, 2012.

FERREIRA, F. H. G. Os determinantes da desigualdade de renda no Brasil: luta de classes ou heterogeneidade educacional? In: HENRIQUES, R. (Org). Desigualdade e pobreza no Brasil. Rio de Janeiro: IPEA, 2000. 
FRIGOTTO, G. Educação e a construção democrática no Brasil: da ditadura civil-militar à ditadura do capital. In: FAVERO, O.; SEMERARO, G. (Org.). Democracia e construção do público no pensamento educacional brasileiro. Petrópolis: Vozes, 2002.

LANGONI, C.G. Distribuição da renda e desenvolvimento econômico no Brasil. Rio de Janeiro: Expressão e Cultura, 1973.

LEHER, Roberto et al. A contrarreforma da Educação Superior: uma análise do andessn das principais iniciativas do governo lula da silva. Publicação do grupo de trabalho de Política de Educação-GTPE/ANDES-SN. Brasília.

NATALINO, Marco Antônio Carvalho. Pesquisa de mobilidade ocupacional e acesso a programas sociais: aspectos teórico metodológicos da avaliação da estratégia brasileira de desenvolvimento social. In: Cadernos de Estudos - Desenvolvimento Social em Debate, 2015.

OIT (ORGANIZAÇÃO INTERNACIONAL DO TRABALHO). Trabalho decente e juventude no Brasil. Brasília: Organização Internacional do Trabalho, 2009.

. Trabalho decente e juventude no Brasil. Brasília: OIT, 2009.

POCHAMANN, Marcio. A batalha pelo primeiro emprego: a situação atual e as perspectivas do jovem no mercado de trabalho brasileiro. São Paulo: Publisher Brasil, 2007.

PNUD. Relatório do desenvolvimento humano: sustentar o progresso humano: reduzir as vulnerabilidades e reforçar a resiliência, 2014.

SANTOS, Francine Helfreich Coutinho. Mercantilização do ensino superior e o Serviço Social brasileiro. In: Serviço Social e Sociedade, n. 102, 2010, p. 387-390.

UNESCO. Declaração Mundial sobre o ensino superior no século XXI.

VASAPOLLO, Lucio. Pobreza típica de trabalho atípico. In: Revista Outubro, 2004.

VIGNOLI, Jorge Rodríguez. Vulnerabilidade demográfica: una faceta de las desventajas sociales. Santiago do Chile: Proyeto Regional de Población CELADE-FNUAP, 2000.

VÉRAS, Maura Pardini. Exclusão Social, um problema de 500 anos: notas preliminares. In SAWAIA, Bader (Org.). As artimanhas da exclusão: análise psicossocial e ética da desigualdade social. 2. ed. Petrópolis, Vozes, 2001.

WAISELFISZ, J. Jacobo. Mapa da Violência III. Brasília: UNESCO; Instituto Ayrton Senna, Ministério da Justiça/SEDH, 2002.

Recebido em: 12/01/2016

Aprovado em: 03/06/2017 